\title{
Nutritional values and acceptability of syrups produced after blending carrots, sweet potatoes, and tomatoes
}

\author{
Ibrahim Mahmoud Ahmed Ibrahim* * and Hamed Mohamed Hassanin Khashaba
}

\begin{abstract}
Background: The artificial syrups on the market are known with many harmful health effects for using unnatural colors and flavors. This study evaluated the effect of different compositions of syrups and storage on the quality and nutritional value of syrups produced from three types of high nutritional vegetables such as carrot, sweet potato, and tomato, at weighting ratios T1 (6:2:2), T2 (5:3:2), T3 (4:4:2), T4 (3:5:2), and T5 (2:6:2). Pasteurization was performed at $85^{\circ} \mathrm{C} / 25 \mathrm{~s}$ for concentrated syrup at $65^{\circ} \mathrm{Brix}$. Physicochemical analyses were applied to the recovered drink at $14^{\circ} \mathrm{Brix}$ every 2 months for 6 months.

Results: Ascorbic acid, carotenoids, lycopene, color values, total phenols, and antioxidant activity gradually decreased in all treatments during storage, while acidity and browning increased. Increasing sweet potatoes about $4 \%$ or decreasing under $3 \%$ harmed the overall acceptability of the syrups.

Conclusion: Finally, the findings revealed that T2 and T3 were the most suitable samples on storage. Therefore, our data recommended producing syrups from carrot, sweet potato, and tomato with the same composition of T2 and T3, which give a more attractive taste and flavor similar to apricot juice.
\end{abstract}

Keywords: Carrots, Sweet potatoes, Tomatoes, Synthetic, Natural syrups

\section{Background}

Artificial or synthetic syrups use artificial coloring and flavoring since they are inexpensive and stable. However, unnecessary intake will lead to serious health problems (Kus and Eroglu 2015). Excessive intake of synthetic pigments and flavors led to burp, migraine headache, allergic and poisonous symptoms (Goodman 2013). A mutating activity that contributes to cancer has also been noticed (Sarikaya et al. 2012). The level of synthetic pigments in foods should be restricted. Synthetic syrups have no therapeutic benefit and nutritional, due to the absence of dietary fiber, minerals, vitamins, and artificial sweeteners sometimes are added as an alternative to sugar. Using of natural materials in a different industrial product

\footnotetext{
*Correspondence: ibrahim256_mah@yahoo.com

Special Food and Nutrition Department, Food Technol Research Institute, Agriculture Research Center, Giza, Egypt
}

becomes a universal trend. Vegetables have important content of bioactive compounds, dietary fiber, attractive color, and flavors (Kongkachuichai et al. 2015), enhanced nutritional value, health properties, and reduced risk of degenerative diseases (Girones-Vilaplana et al. 2016; Hussein et al. 2017). Developing a new product by mixing two or more types of fruit or vegetables can improve market popularity and achieve excellent color and flavor as well as economical manufacturing (De Carvalho et al. 2017). Carrot (Daucus carota L.) has a higher level of carotenoids, phenols, and flavonoids in addition to vitamins and minerals (Da Silva et al. 2007; Sharma et al. 2012).

Sweet potatoes include vital antioxidants like ascorbic acid, $\beta$-carotene, phenolics, tocopherols, folates, and flavonoids as well as dietary fiber (Fernandez-Orozco et al. 2013). Carotenoids in carrots as well as sweet potatoes 
have demonstrated various biological activities (Dhiman et al. 2017; Olagunju and Sandewa 2018).

Tomatoes have several antioxidants like $\beta$-carotene, ascorbic acid, lycopene, tocopherols, and total phenols (Perago et al. 2009). Lycopene is one of the antioxidants that have an activity that exceeds both $\alpha$ - and $\beta$-carotene and prevents many diseases due to the inhibitory effect of cell breakdown and strengthening it (George et al. 2004; Sharoni and Levi 2006). Vitamin E in tomatoes displayed a higher activity against LDL oxidation and caused atherosclerotic and carcinogenic (Brigelius-Flohe et al. 2002). This study developed new natural syrups from different kinds of vegetables that enhance flavor and color characteristics in addition to improve nutritional value and health benefits.

\section{Methods}

Fresh carrots (Daucus carota L.), sweet potatoes (Ipomoea batatas L.), and tomatoes (Lycopersicum esculentum) fruit are obtained from a local market in Ismailia, Egypt. The carrots and sweet potatoes have an orange pulp color while the tomato is selected in terms of ripeness and shape. DPPH (2, 2 -diphenyl-1-picrylhydrazyl) and Folin-Ciocalteu gained from Sigma-Aldrich (St, Louis, USA). Both analytical grade solvents and chemicals bought from Sigma Chemical Corporation, Egypt.

\section{Preparing carrot, sweet potato, and tomato pulps}

The running tap water was used to wash and remove dirt and impurities of carrot as well as sweet potato, then the outer shell and the thrones were removed, and the carrot was washed by the water well. The carrot put in a pot with immersion in water and boiled for $20 \mathrm{~min}$ to soften each tissue with applied the same procedures on sweet potato. The hand mixer was used for carrots to get the pulp. Sweet potatoes were peeled by hand and then manually mashed. The tap water was used to wash fresh tomatoes then dried in the air and pulped with a Moulinex juice extractor (type, 753, Moulinex, Spain). Tomato pulp was obtained by filtration through stainless steel strainers.

\section{Preparing carrot, sweet potato, and tomato syrups}

Carrot, sweet potato, and tomato pulps were combined at a weighting ratio of 6:2:2 (T1), 5:3:2 (T2), 4:4:2 (T3), 3:5:2 (T4), and 2:6:2 (T5); the sugar was used to concentrate the blends to $65^{\circ}$ Brix. Sodium benzoate was used to syrups by $1 \mathrm{~g} / \mathrm{kg}$, while the concentration solution of citric acid was used to change the $\mathrm{pH}$ to 4 . The syrup was pasteurized at $85{ }^{\circ} \mathrm{C} / 25 \mathrm{~s}$, hot filled in glass bottles, capped, and placed in a water bath at $85^{\circ} \mathrm{C}$ for $15 \mathrm{~min}$ to kill spoiling microorganisms. The cold water was used to cool glass bottles to room temperature, and samples were taken for analysis after processing and every 2 months after that.

\section{Assessment of Brix, $\mathrm{pH}$, total acidity, and vitamin $\mathrm{C}$}

The Abbe refractometer was used to determine the degree of ${ }^{\circ}$ Brix at $20^{\circ} \mathrm{C}$. Jenway $3510 \mathrm{pH}$ meter (UK) was used to detect the $\mathrm{pH}$ value. Total acidity (TA) was measured by titrating of diluted syrup at $14^{\circ}$ Brix with sodium hydroxide at concentration $0.1 \mathrm{~N}$ for $\mathrm{pH} 8.1$ (the findings expressed as \% citric acid) (AOAC 2000). Vitamin C was measured using the 2,6-dichlorophenolindophenol dye solution by titration method (AOAC 2000).

Assessment of total phenols (TP), antioxidant activity (AA), beta-carotene, lycopene, and browning

Folin-Ciocalteu was used to determine total phenolic compounds as described by Osorio-Esquivel et al. (2011). DPPH was employed to assess antioxidant activity, identical to the way Ravichandran et al. (2013). $\beta$-Carotene content was measured as described by Barros et al. (2011) using a mixture of hexane: acetone (6:4, v/v). The method of Barrett and Anthon (2001) was utilized to estimate lycopene. The method of Ranganna (2010) was used to measure the browning.

\section{Assessment of color}

Color reader CR-10 (Konika Minolta, Inc., Osaka, Japan) was utilized to measure color parameters $L^{*}$ (transparency), $a^{*}$ (red to green), and b* (yellow to blue).

\section{Sensory attributes}

All sensory evaluations of different tested diluted syrups achieved using the method of Howard and Dewi (1995) by ten staff members (semi-trained panelists) for taste (10), odor (10), color (10), mouth feel (10), and appearance (10). Overall acceptability calculates as the average of total scores.

\section{Statistical analysis}

The data obtained were subjected to variance analysis (ANOVA) using COSTAT (CoHort software version 6.303) at $P=0.05$. The mean of different treatments was compared by Duncan's test at $P=0.05$.

\section{Results}

\section{pH and acidity}

Figure 1 shows the influence of storage and treatments on the $\mathrm{pH}$ and acidity of dilution syrup at 14 Brix. $\mathrm{pH}$ decreased up to 4 or less was an essential factor in preserving syrups against microbial spoilage. The $\mathrm{pH}$ value varied from 3.91 to 3.98 at zero time. The existing data showed that T2 and T3 had higher $\mathrm{pH}$ values. Throughout storing for 6 months, the $\mathrm{pH}$ value decreased, and the 

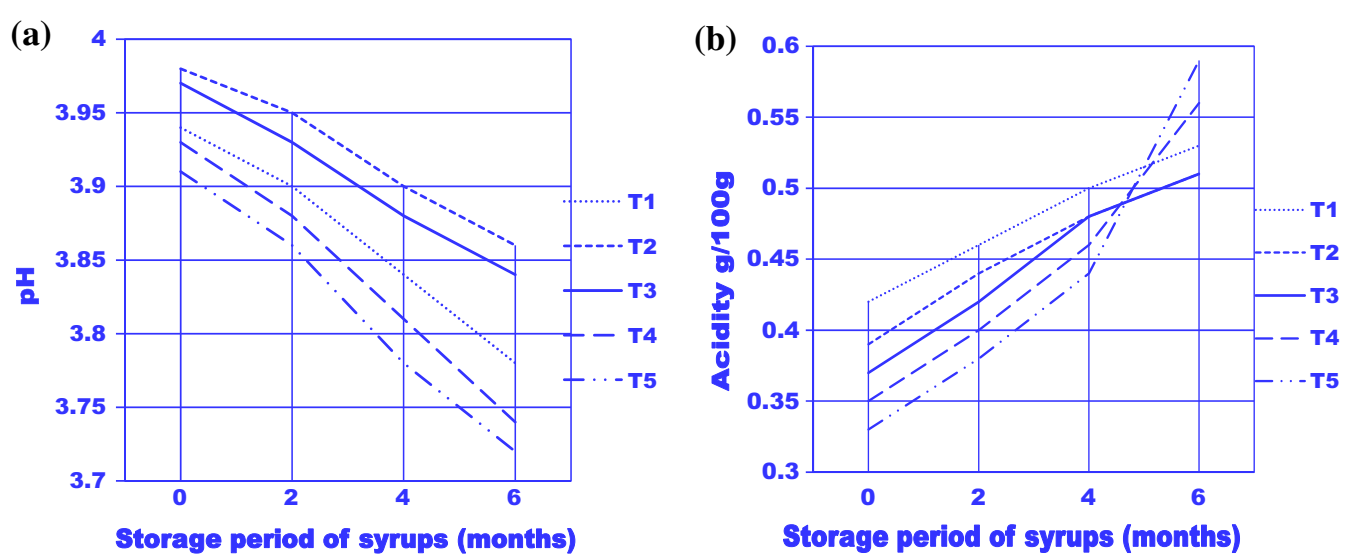

Fig. 1 Change in $\mathrm{pH}$ and acidity in different syrups during the storage period

acidity increased in all treatments. $\mathrm{T} 2$ and $\mathrm{T} 3$ recorded the maximum $\mathrm{pH}$ value while $\mathrm{T} 5$ and $\mathrm{T} 4$ registered the minimum level compared with the other treatments.

\section{Ascorbic acid}

Changing in ascorbic acid content is shown in Fig. 2a. The thermal process during pasteurization effected on ascorbic acid retention in addition to storage periods. T1 recorded maximum ascorbic acid retention after preparation syrups and pasteurized. T1 was the highest ascorbic acid retention (98\%) at zero time against $90 \%$ for the lowest one (T3). There was a gradual decrease in the level of ascorbic acid detected during storage. By storage ending, $\mathrm{T} 1$ and $\mathrm{T} 2$ had the maximum of vitamin $\mathrm{C}$ retention (71 and $60 \%$ ) of the original amount at zero times.

\section{Browning (non-enzymatic browning)}

Figure $2 \mathrm{~b}$ shows the development of polymerized color and browning. The browning varied from 0.025 to 0.045 at zero time for all treatments. The increasing amount of carrots had a positive relation with browning increasing. T5 has the lowest browning compared to the rest treatments at zero time. Browning increased gradually in syrups by increasing the time of storage progressively. T2 and T3 (0.113 and 0.120) had the lowest browning after the storage period, while the increase in browning of $\mathrm{T} 5$, T4, and T1 was more noticeable.

\section{Total phenolics content (TP)}

The differences between TP for different treatments were insignificant at zero time, as shown in Fig. 3a. During storage, the TP content dropped in all treatments. T2 and T3 recorded higher retention of TP with value $(76 \%$ and $74 \%)$. The retention rate of the TP value of T5 was $55 \%$ compared to $\mathrm{T} 4$ and $\mathrm{T} 1$ (68\% and $69 \%)$, respectively.

\section{Carotenoids}

The data regarding the influence of storage on carotenoid retention in diluted syrups are shown in Fig. 3b. The findings exhibit that the retention rate for all treatments
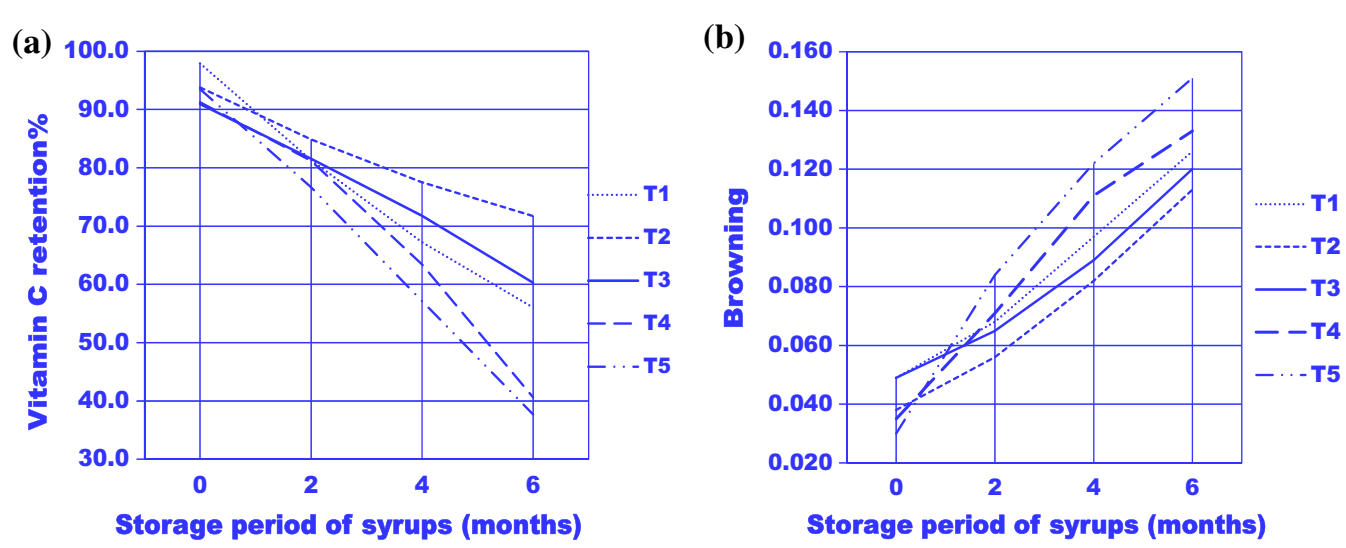

Fig. 2 Change in vitamin C and browning in different syrups during the storage period 

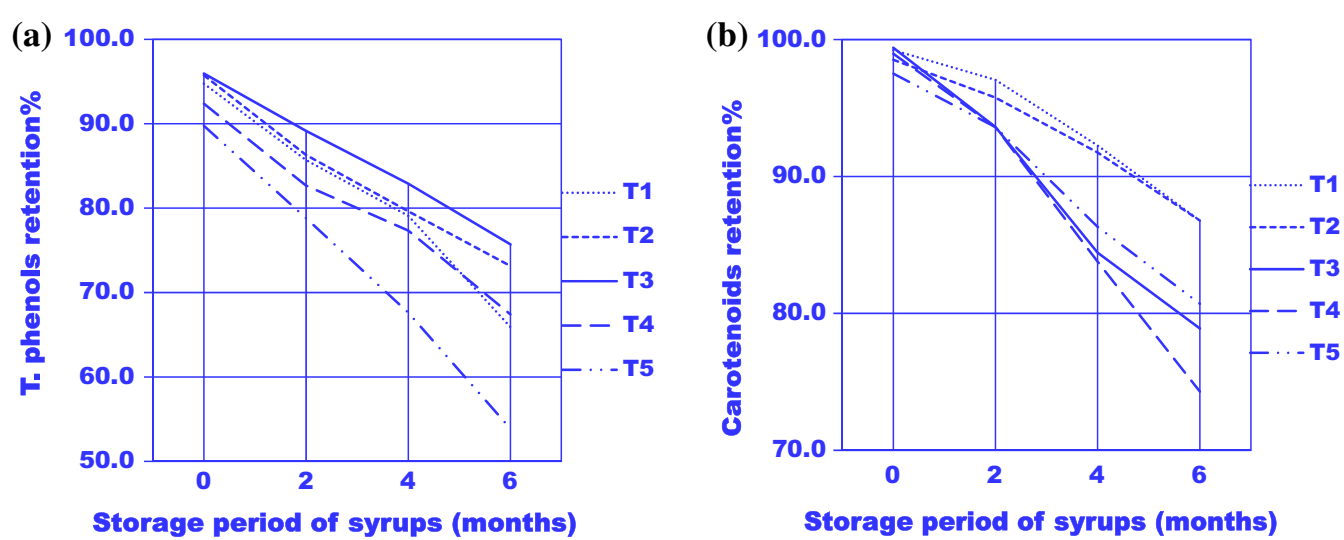

Fig. 3 Retention of total phenols and carotenoids in different syrups during the storage period

varied from (98-99\%) at zero time immediately after processing. All syrups had the same decreasing pattern in carotenoids through 6 months of the store. T1 and T2 recorded the highest $\beta$-carotene retention (88\%) compared to T5 and T3 (82\% and 79\%) after 6 months of storage. T4 was the lowest retention rate of $\beta$-carotene after 180 days of an ambient store with a retention rate of $75 \%$. By storage ending, samples containing 5 and $4 \%$ carrots were the most carotenoids maintained relative to sample comprising 6,3 , and $2 \%$ carrots in their composition.

\section{Lycopene}

The changes in lycopene syrups are presented in Fig. 4a. The lycopene retention in syrup samples had small changes at zero time, due to the constant percentage of the tomato pulp applied to the syrup composition of the five samples. The T2 lycopene retention rate equaled $\mathrm{T} 5$, and they recorded the maximum lycopene retention rate compared to the rest samples. The retention rate of lycopene decreased during storage to
65-88\% compared to $96-98 \%$ at zero time, with losses varying from 10 to $31 \%$, where $\mathrm{T} 2$ had the maximum rate of lycopene retention (88\%) and $\mathrm{T} 5$ had the lowest retention rate $(65 \%)$.

\section{Antioxidant activity (AA)}

Figure $4 \mathrm{~b}$ shows the decrease in total antioxidant activity in different treatments during the storage period. The AA was ranged between 87 and $99 \%$ for the various treatments at zero time. T3 was the best treatment at zero time, which recorded the highest retention with total antioxidant activity, while T4 was the worst. As storage continued, the AA rate was reduced in different samples. The retention rate of AA ranged from $65-88 \%$ against $87-99 \%$ at zero time, with a loss rate of between 11 and $22 \%$. T3 still recorded the maximum retention rate with AA (88\%) compared with other treatments throughout storage.
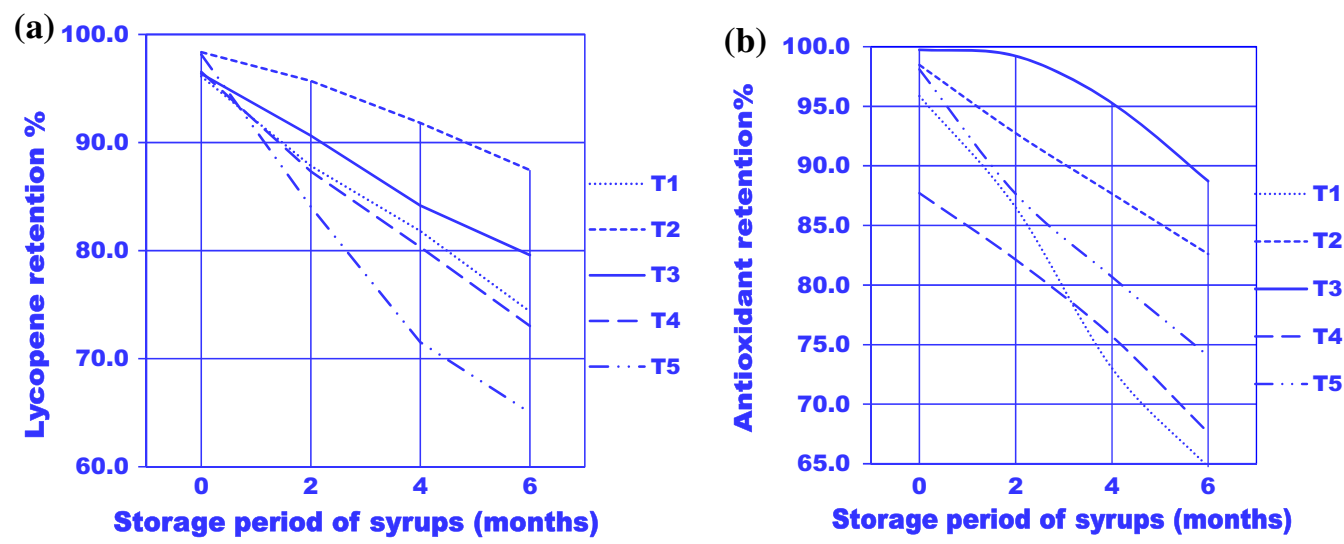

Fig. 4 Retention of lycopene and antioxidants activity in different syrups during the storage period 


\section{Color evaluation}

The surface color, $\mathrm{L}^{*}$ or transparency (brightness to darkening), $a^{*}$ (redness), and b* (yellowness) values of diluted syrups were measured and are pointed in Fig. 5. The level of transparency, redness, and yellowness are linking to visual panel effects and shelf life dependent on color shifts. $L^{*}$ (transparency) values ranged from 42.2 to 45.9 at zero time. Transparency value increased (increase brightness) with increases in the content of sweet potatoes in the sample, while the transparency decreased (increase darkening) with an increase in the carrots percent.

The ratio of $2: 6: 2$, T5 recorded the maximum transparency at zero time. Differences at a* (red color) were detected between different treatments at zero time. The value of $b^{*}$ (yellow color) is proportional to carotenoids so that more carotenoids responsible for yellow and orange contributed to an increase in yellowness or $\mathrm{b}^{*}$, which is a measurement of the color from yellow (100) to blue $(-100)$. The findings reveal that with a rise in carrots in syrups, the color rises to the orange color at zero time. The value of yellowness decreased from T1 to T5. During storage for 6 months, the values of transparency, redness, and yellowness of all diluted syrups decreased dramatically. Slightly darkening developed in the syrup as a result of a Millard reaction between sugars and amino acids. Higher carotenoids, lycopene, and brightness were reported (5:3:2, T2 and 4:4:2, T3). The findings showed that T2 and T3 syrups were a more suitable color compared with the rest syrups.

\section{Sensory evaluation}

Figure 6 illustrates the organoleptic features of various syrups at the start and end of the storage. Color, taste, odor, mouthfeel, and appearance are the most sensory attributes that influence the acceptability of syrups and customer approval or rejection. The highest overall acceptability score (9.1) was given by $\mathrm{T} 1$, which the panelists chose as more acceptable at zero time. T2 and T3 came out with scores after T1 (9.0 and 8.9). T4 and T5 (8.6) registered the lowest scores.

The mean score for color, odor, taste, mouthfeel, appearance, and total acceptance of various syrups continuously decreased significantly during storage under ambient storage, because of the production of the browning, the color score reduced, making the appearance of the product less desirable to the panelists. All syrups had a higher acceptance score even after the storage period. Finally, the most favorable sample by the panelists was the T2 followed by T3. Therefore, it is highly recommended using them for commercial production due to their attractive color and flavor. Further relationships between all analyses parameters confirmed the superiority of these two treatments, as shown in Fig. 7. These links are explained in discussion section. It is also clear from the influence of different treatments and storage period on the final quality of syrups.

\section{Discussion}

Acidity has a positive relationship with taste, as seen by the findings after 6 months; the best tasting treatments (T1, T2) had the lowest acidity at zero time. Increasing acidity and $\mathrm{pH}$ decrement during storage are due to pectin degradation to pectic acid or sugar degradation (Supraditareporn and Pinthong 2007; Ayub et al. 2010). Ahmed et al. (2019) have reported the same pattern of findings in peach juices stored for 90 days.

The level of ascorbic acid has a good indicator of the quality and nutritional value of syrups after the thermal process and storage. The lack of ascorbic acid during
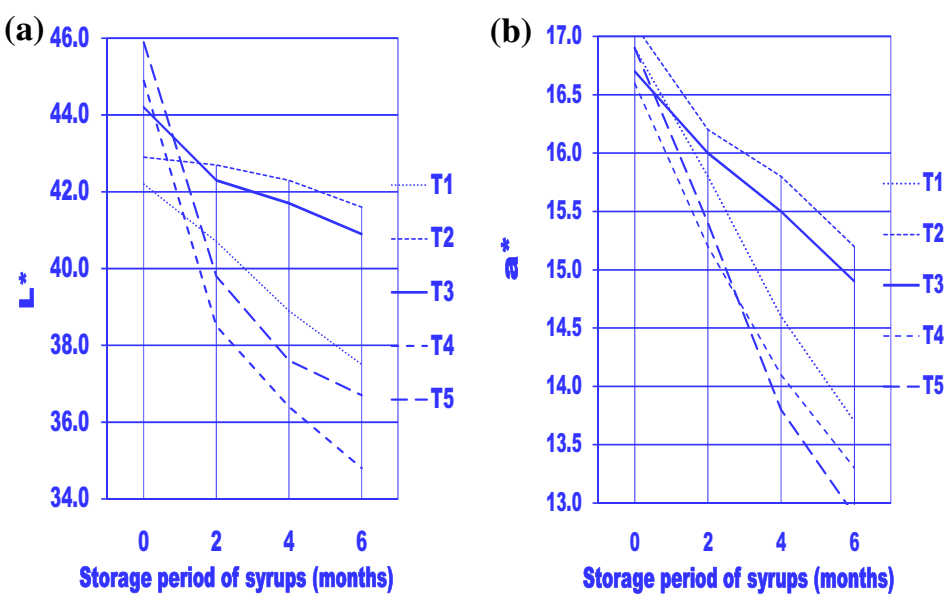

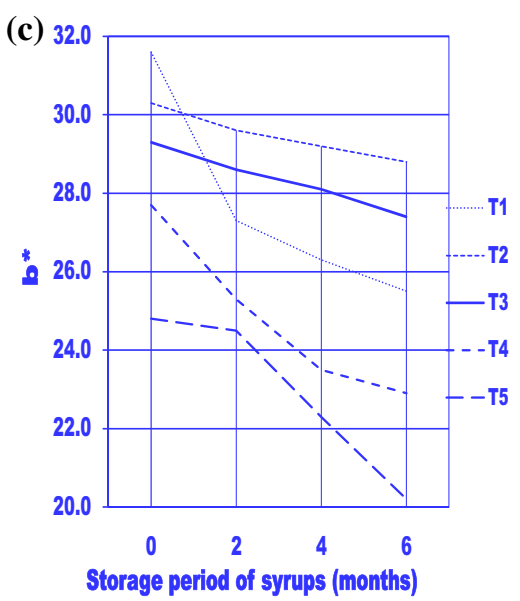

Fig. 5 Hunter's values $\left(L^{*}, a^{*}, b^{*}\right)$ in different syrups during the storage period 


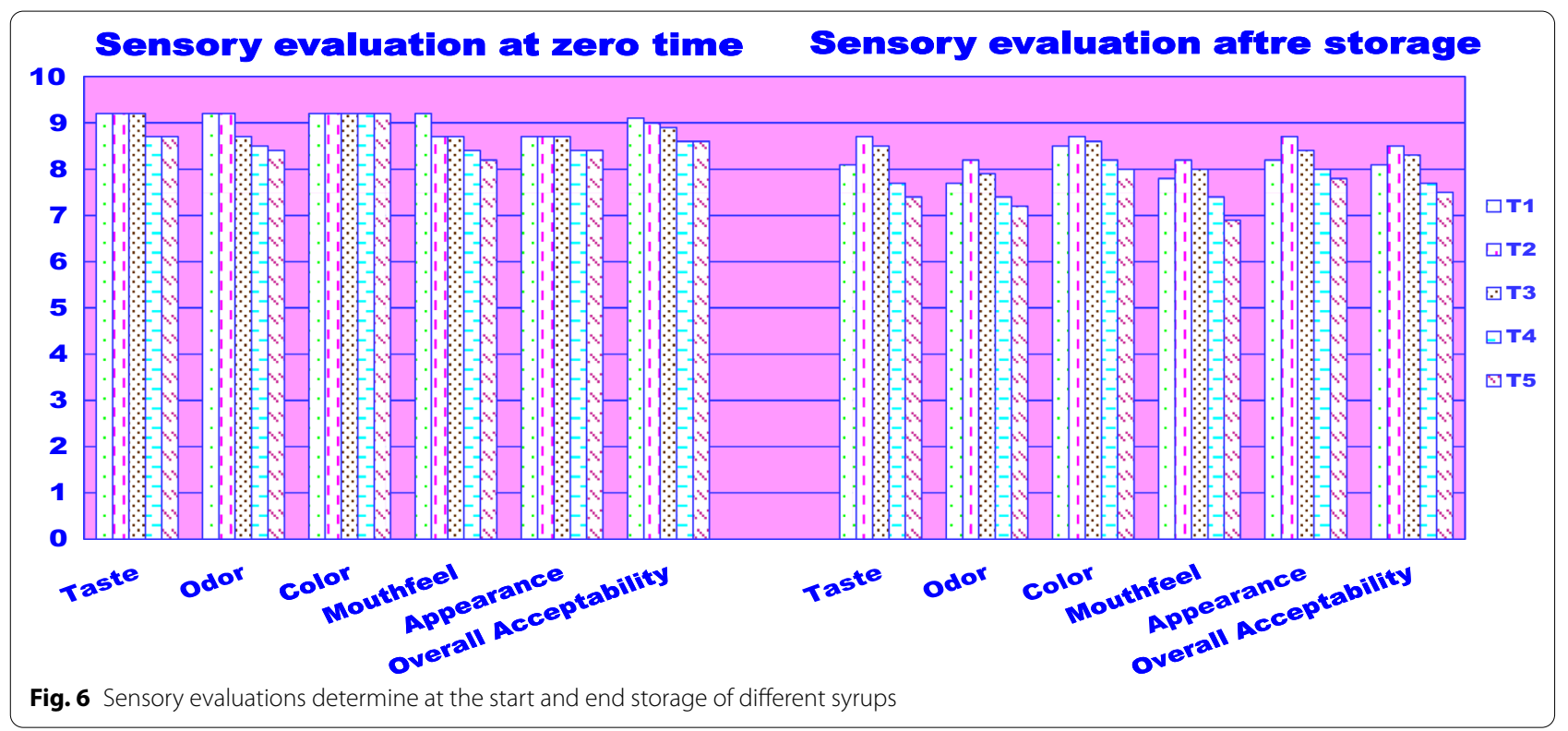

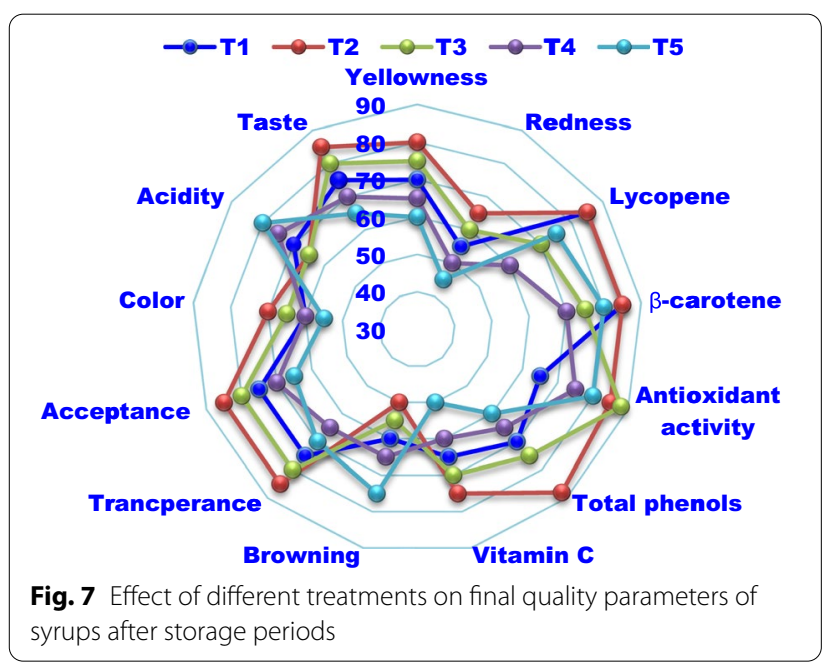

storage is related by the reduction of $L^{*}$ (transparency) and increasing browning (non-enzymatic browning). The preference of the samples regarding ascorbic acid maintenance is $\mathrm{T} 2, \mathrm{~T} 3, \mathrm{~T} 1, \mathrm{~T} 4, \mathrm{~T} 5$, which resulted same in transparency and browning reduction. The reduction in ascorbic acid of all syrup blends during storage is due to ascorbic oxidation and light exposure. The present findings are compatible with those of Embaby and Mokhtar (2019) for carrot-goldenberry nectar blends after 28 days of storage at $4{ }^{\circ} \mathrm{C}$.

Increasing the bioactive compounds like lycopene and carotenoids was improved transparency and reduction in the browning. The preferred findings of $\mathrm{T} 2$ showed the lowest browning rate and improved color transparency due to an increase in lycopene and carotenoid levels. Overall, all four parameters decreased by the end of storage, except browning that increased. The changes in browning during storage are mainly due to non-enzymatic browning or oxidation of phenols, which leads to an increase in the browning as reported by Bhardwaj and Mukherjee (2011) for kinnow juice and Adeogun et al. (2017) for sweet orange juice. Also, Mokhtar and Ibrahim (2020) reported the same increase in the browning index of guava nectar during the 6-month storage at room temperature. The reduction in carotenoids over storage is due to the auto-oxidative degeneration or isomerization (Alkesh 2005; Sharma et al. 2009). Dhiman et al. (2017) stated similar findings on pumpkin beverages.

The findings showed a strong connection among the level of TP and AA, as shown in the T2 measurements, obtained the highest value of TP as well as a good AA after storing. Decreased TP and AA after storage of all syrup mixtures can be due to the condensation of polyphenols into brown pigments. Existing results are close to those of Sharma et al. (2019) on the apple-whey beverage.

Slight variations were observed in lycopene and $\mathrm{a}^{*}$ (redness) value between different treatments at zero time due to the stable percent of tomatoes addition. Correlation between $\mathrm{a}^{*}$ (redness) and lycopene was monitored by storage end; the sample contains a higher amount of lycopene such as $\mathrm{T} 2$ which recorded the maximum redness. Also, the increase in the percent of carrots added significantly increased yellowness $\left(b^{*}\right)$. The maximal carrot content was raised the yellow color as in the T1 at zero time. The rise percent of sweet potatoes greater than 4 percent resulted in a strong odor of sweet potatoes in a blend as in T4, T5, 
whereas the percentage under 4 gave an odor close to that of apricot juice.

The color attributes are affected by transparency $\left(\mathrm{L}^{*}\right)$, redness $\left(a^{*}\right)$, yellowness $\left(b^{*}\right)$, vitamin $C$, total phenols, $\beta$-carotene, and lycopene. Increasing all previous parameters achieved the best color. Decreasing transparency, redness, and yellowness values of all diluted syrups dramatically lowered the average overall acceptability by storage end. The same findings were obtained by Elik et al. (2016), Ahmed et al. (2019), Sharma et al. (2019) during the storage of different types of juices.

\section{Conclusion}

The syrups prepared from carrots and sweet potatoes and tomatoes have higher acceptance of taste, color, flavor, and low production costs due to its production from locally available cheaper materials. Therefore, our data recommended by production the syrups from carrot, sweet potato, and tomato with the same composition of $\mathrm{T} 2$ and T3, which give a more attractive taste and flavor similar to apricot juice.

\section{Abbreviations}

TA: Titrable acidity; TP: Total phenols; AA: Antioxidant activity.

\section{Acknowledgements}

The authors are grateful to the Agriculture Research Center for providing all required facilities to complete this work. Many thanks to Dr. Sayed Mohamed Mokhtar in the Department of Food Technology, Faculty of Agriculture, Suez Canal University, Ismailia, Egypt, for providing the required help not only in the laboratory but also in the experimental field.

\section{Authors' contributions}

IMAI designed the study, analyzed, interpretation of the data, and was a major contributor in writing the manuscript. HMHK participated in the design of the study, the analysis, and revised the manuscript. All authors read and approved the final manuscript.

\section{Funding}

All authors equally shared in financing the cost of the research paper.

\section{Availability of data and materials}

All the data obtained during the study are presented in this manuscript. Any further enquiries for additional information are available upon request from the corresponding author.

\section{Ethics approval and consent to participate}

Not applicable.

\section{Consent for publication}

Not applicable.

\section{Competing interests}

The authors declare that they have no competing interests.

Received: 23 July 2020 Accepted: 18 October 2020

Published online: 30 October 2020

\section{References}

Adeogun OO, Adekunle AA, Adongbede EM (2017) Effects of leaf extracts of selected plants on quality of stored Citrus sinensis (sweet orange) juice. Notulae Scientia Biologicae 9:256-262

Ahmed U, Ahmad RS, Mushtaq Z, Hussian SM (2019) Characterization of low calorie ready-to-serve peach beverage using natural sweetener, Stevia (Stevia rebaudiana Bertoni). J Nutr Internal Med 21(1):435-444

Alkesh (2005) Production of carotenoids as food colourants from natural sources. Ph.D. Thesis, Horticulture and Forestry University, Nauni, Solan, India

AOAC (2000) Official methods of analysis, 16th edn. Association of Official Analytical Chemists, Washington

Ayub M, Ullah J, Muhammad A, Zeb A (2010) Evaluation of strawberry juice preserved with chemical preservatives at refrigeration temperature. Int J Nutr Metab 2:027-032

Barrett DM, Anthon GE (2001) Lycopene content of California-grown tomato varieties. Acta Hort 542(7):165-174

Barros L, Cabrita L, Boas MV, Carvalho AM, Ferreira IC (2011) Chemical, biochemical and electrochemical assays to evaluate phytochemicals and antioxidant activity of wild plants. Food Chem 127:1600-1608

Bhardwaj RL, Mukherjee S (2011) Effects of fruit juice blending ratios on kinnow juice preservation at ambient storage condition. Afr J Food Sci 5:281-286

Brigelius-Flohe R, Kelly FJ, Salonen JT, Neuzil J, Zingg JM, Azzi A (2002) The European perspective on vitamin $\mathrm{E}$ : current knowledge and future research. Am J Clin Nutr 76:703-716

Da Silva AQ, Vieira MA, Vieira EA, Amboni RD, Amante ER, Teixeira E (2007) Chemical, physical, and sensory parameters of different carrot varieties (Daucus carota L.). J Food Proc Eng 30:746-756

De Carvalho JM, Maia GA, De-Figueredo RW (2017) Development of a blended nonalcoholic beverage composed of coconut water and cashew apple juice caffeine. J Food Quality 30:664-681

Dhiman AK, Negi V, Attri S, Ramachandran P (2017) Optimization of instant halwa mix from dehydrated pumpkin and its stability during storage. Int J Agric Sci 9(11):4026-4030

Elik A, Yanik DK, Maskan M, Gogus F (2016) Influence of three different concentration techniques on evaporation rate, color and phenolics content of blueberry juice. J Food Sci Technol 53(5):2389-2395

Embaby HES, Mokhtar SM (2019) Impact of adding goldenberry (Physalis peruviana $\mathrm{L}$.) on some quality characteristics and bio-functional properties of pasteurized carrot (Daucus carota L.) nectar. J Food Sci Technol 56:966-975

Fernandez-Orozco R, Gallardo-Guerrero L, Hornero-Méndez D (2013) Carotenoid profiling in tubers of different potato (Solanum sp.) cultivars: accumulation of carotenoids mediated by xanthophyll esterification. Food Chem 141:2864-2872

George B, Kaur C, Khurdiya DS, Kapoor HC (2004) Antioxidants in tomato (Lycopersium esculentum) as a function of genotype. Food Chem 84:45-51

Girones-Vilaplana A, Huertas JP, Moreno DA, Periago PM, Garcia-Viguera C (2016) Quality and microbial safety evaluation of new isotonic beverages upon thermal treatments. Food Chem 194:455-462

Goodman DW (2013) Artificial food colour exclusion and free fatty acid supplementation 293 may reduce symptom severity in children with ADHD. Retrieved on 13-5-2013 from https://doi.org/10.1136/eb-2013-101332

Howard LR, Dewi T (1995) Sensory, microbiological and chemical quality of mini-peeled carrots as affected by edible coating treatment. J Food Sci 60(1):142-144

Hussein AMS, Hegazy NA, Kamil MM, Ola SSM (2017) Formulation and evaluation of some healthy natural juice blends. Asian J Scient Res 10:160-168

Kongkachuichai R, Charoensiri R, Yakoh K, Kringkasemsee A, Insung P (2015) Nutrients value and antioxidant content of indigenous vegetables from Southern Thailand. Food Chem 173:836-846

Kus E, Eroglu HE (2015) Genotoxic and cytotoxic effects of Sunset Yellow and Brilliant Blue, colorant food additives, on human blood lymphocytes. Pak J Pharm Sci 28(1):227-230

Mokhtar SM, Ibrahim IMA (2020) Physicochemical, antioxidant and sensorial properties of pasteurized guava nectar incorporated with pomegranate peel and guava leaf extracts. World J Food Sci Technol 4(1):8-16

Olagunju Al, Sandewa OE (2018) Comparative physicochemical properties and antioxidant activity of dietary soursop milkshake. Beverages 4(2):38 
Osorio-Esquivel OA, Lvarez VB, Dorantes A, Lvarez L, Giusti MM (2011) Phenolics, betacyanins and antioxidant activity in Opuntia joconostle fruits. Food Res Int 44:2160-2168

Periago MJ, García-Alonso J, Jacob K, Olivares AB, Bernal AJ, Iniesta MD (2009) Bioactive compounds, folates and antioxidant properties of tomatoes (Lycopersicum esculentum) during vine ripening. Int J Food Sci Nutr 60(8):694-708

Ranganna S (2010) Hand book of analysis and quality control for fruit and vegetable products. McGraw-Hill, New Delhi

Ravichandran K, Saw NM, Mohdaly AA, Gabr AM, Kastell A, Riedel H, Cai Z, Knorr D, Smetanska I (2013) Impact of processing of red beet on betalain content and antioxidant activity. Food Res Int 50:670-675

Sarikaya R, Selvi M, Erkocc F (2012) Evaluation of potential genotoxicity of five food dyes using the somatic mutation and recombination test. Chemosphere 88(8):974-979

Sharma M, Gehlot R, Singh R, Siddiqui S (2009) Studies on physico-chemical composition fresh guava and jamun fruits. Haryana J Hortic Sci 38(1):68-69
Sharma M, Gehlot R, Singh R, Siddiqui S (2012) Changes in chemical constituents and overall acceptability of guava jamun blend RTS drink and squash during storage. Beverage Food World 39(4):39-42

Sharma P, Choudhary R, Thakur NS, Thakur A (2019) Development and quality of apple-whey based herbal functional ready-to-serve beverage. J Appl Nat Sci 11(2):291-298

Sharoni Y, Levi Y (2006) Cancer prevention by dietary tomato lycopene and its molecular mechanisms. In: Rao AV (ed) Tomatoes, Lycopene and Human Health. Caledonian Science Press Ltd., Barcelona, pp 111-125

Supraditareporn W, Pinthong R (2007) Physical, chemical and microbiological changes during storage of orange juices cv. Sai Nam Pung and cv. Khieo Waan in Northern Thailand. Int J Agric Biol 9:726-730

\section{Publisher's Note}

Springer Nature remains neutral with regard to jurisdictional claims in published maps and institutional affiliations.

\section{Submit your manuscript to a SpringerOpen ${ }^{\circ}$ journal and benefit from:}

- Convenient online submission

- Rigorous peer review

- Open access: articles freely available online

- High visibility within the field

- Retaining the copyright to your article

Submit your next manuscript at $\boldsymbol{\nabla}$ springeropen.com 